\title{
MULTINOMIAL LOGIT MODEL ESTIMATION OF HOUSEHOLD CHARACTERISTICS INFLUENCING CAR OWNERSHIP IN AKURE, SOUTH WEST, NIGERIA
}

\author{
Oyedepo Olugbenga Joseph ${ }^{1}$, Etu Japheth Eromietse ${ }^{2}$, De Souza Emmanuel ${ }^{3}$, Afolabi \\ Olufunke ${ }^{4}$ \\ 1,2,3,4 Department of Civil and Environmental Engineering, Federal University of Technology, Akure Ondo \\ State, Nigeria
}

Received 17 November 2016; accepted 19 April 2017

\begin{abstract}
Understanding and predicting factors affecting car ownership and use is important given its impacts on transportation planning. This study investigates contributing factors to car ownership in Akure. The study's data were gotten through the administration of a wellstructured questionnaire survey from May-July 2016 to households in the city. The study area was divided High, Medium and Low population density zones with the survey yielding a return of 1002 questionnaire out of the 1181 distributed. SPSS 22 was used for both descriptive statistical analysis and formulation of the Multinomial Logit Model of car ownership. Model estimates shows that the probability of owning a car increases with increase in income (I2) and reduces with increase in household members (HN). Sensitivity analysis was carried out with the model estimates to test different scenarios. The test results show that a $50 \%$ increase in income and Number of household members increases the number of cars owned in Akure metropolis by $51 \%$ and $0.8 \%$ respectively while a decrease in $\mathrm{I} 2$ and $\mathrm{HN}$ by $50 \%$ reduces the number of cars owned by $37 \%$ and $0.8 \%$ respectively. R-square value of 0.705 and P-value of 0.000 implies that the model gives a good prediction. The study has shown that car ownership will increase with increase in earning capacity of households in Akure such as in the periods of economic boom while the reverse is the case in periods of recession. The results will assist transportation planners and agencies in solving urban traffic problems in the city.
\end{abstract}

Keywords: multinomial, logit, ownership, model, household, sensitivity analysis.

\section{Introduction}

The process of rapid urbanization in Africa and in Nigeria in particular has resulted into pressure on urban land as well as urban utilities and services. The rate of urbanization has been so high that urban management functions in form of provision and operations of these utilities and services necessarily lagged behind (Egunjobi, 2002). The rapid urbanization has also led to increase in the number of cars owned by residents without commensurate increase in the number of transport facilities and infrastructures. In a typical Nigerian city for example the transportation system is chaotic, where an estimated 50 percent of houses in the traditional core are not accessible

${ }^{1}$ Corresponding author: e.japheth.e@gmail.com 
to vehicular traffic. Even though, the role of urban transportation is to facilitate the movement of people and goods comfortably and safely, when they are required and recognizing that there is no alternative to mobility, what exists in the Nigerian cities are a litany of inconvenience, and frustration as evidenced in road congestion, pollution, accidents - all of which are fatal to the quality of life in cities (Osita et al., 2003).

In recent years, there has been a noticeable ascendancy in the number of private cars on urban roads in Akure. This is attested to by the car registration records of the vehicle licensing department in Akure. The high population of cars on urban roads often leads to accidents and the formation of long platoons of cars at road intersections during rush hours (Eno, 2007). According Owolabi (2009) the traffic composition in the city is dominated by taxis (cars). Similarly, Oyedepo (2014) asserts that cars are the dominant mode of transportation in Akure metropolis, with about $49.82 \%$ of the traffic composition in the city.

In Nigeria, urban areas, like Akure, are locations having a high level of accumulation and concentration of economic activities. The most important transport problems are often related to such urban areas and take place when the transport systems can not satisfy the demand of the urban mobility (Rodriguez, 2013). Increasing mobility demand has resulted in growing levels of motorization, congestion and pollution. Modern societies are still highly dependent on private vehicles to satisfy demand for activities, while the fastest growing economies in the world are experiencing a rapid increase in motor vehicle ownership. It is clear that vehicle demand has to be optimally managed and regulated in order to reduce the adverse impacts of transportation. In this context, the role of analysts and researchers is to expand the basic knowledge of the problem, to develop better analytical tools and to support decision makers in their strategic choices, (Cirillo and Liu, 2013),

Understanding and predicting consumers' preferences regarding vehicle ownership and use is important given the consequent impacts on both transportation, land-use planning and the relationship to energy consumption, environment and health (Sinha, 2003). The decision by a household to own a first or additional vehicle can be based on a variety of factors, with commonly cited reasons including household location, workplace location, lifestyle commitments and personal status. (Dargay, 2002). Coupled with these factors is whether the household has sufficient income to purchase, maintain and accommodate the vehicle. Due to the observed increase and continuous growth in the number of cars owned in many Nigerian cities and given the importance of car ownership in determining individual and household travel behaviour, it is important to assess the impact of various factors on car ownership.

To this end, this study is focused on determining and understanding factors influencing car ownership in Akure metropolis. Its objective is to develop a statistical model of car ownership behaviour in Akure using household data obtained from a questionnaire survey conducted between the months of May-July, 2016 in some selected households within the study area. It applies the Multinomial Logistic Model in estimating the influence of some selected factors on different car ownership levels $(0$, $1,2,3$ and 4 or more) and also estimating the probability outcomes of the various levels 
based on changes in any of the factors. It is expected that the results of the study will aid better transportation planning in the city, as well as aid in formulating a policy framework to control car ownership so as to solve transportation problems in the city.

\subsection{Background}

Models for car ownership are of interest to both public agencies and private organizations. The US Department of Energy, the State Departments of Transportation, the auto industry, and the World Bank have supported studies on vehicle ownership and used their results for policy analysis (Train, 1986). Models for car ownership growth in developing countries are important to estimate the implications on energy demand and price and on the global CO2 emissions (Dargay and Gately, 1999). Vehicle ownership models are also used by policy makers to identify factors that affect ownership and therefore address the problems related to traffic congestion, gas consumption and air pollution (Dargay and Gately, 1999).

According to Cirillo and Liu (2013), models for predicting changes in the level of vehicle ownership have been developed and applied in several countries such as: The Netherlands, Norway, the U.K., Australia, the United States, Singapore and Malaysia.

Choo and Mokhtarian (2004) identified travel attitude, personality, lifestyle, and mobility factors that influences individual's vehicle type choices, using data from a 1998 mail-out/mail-back survey of 1904 residents in three neighborhoods in the San Francisco Bay Area. Vehicle type was classified into nine categories based on make, model and vintage of a vehicle, small, compact, mid- size, large, luxury, sports, minivan/van, pickup, and SUV. The study developed a multinomial logit model for vehicle type choice to estimate the joint effect of the key variables on the probability of choosing each vehicle type. Furthermore, Whelan (2001) predicted household's decision to own zero, one, two or three or more vehicles as a function of income (modified by eight household categories and five area types), license holding, employment, the provision of company vehicles, and purchase and use costs. The models were applied using a methodology known as prototypical sampling. This method allowed the application of disaggregate models to 1203 zones to the year 2031 taking into consideration changes in the demographic characteristics of each forecast area. The models were successfully validated at the household level and the model forecasts compared favorably with actual ownership information extracted from the 2001 Census. A study was conducted in Taipei Taiwan by Hsu and Lin (2007), investigating both car and motorcycle ownerships with 336 samples using multinomial logit model. The study was based on the assumption that when both a car and a motorcycle are owned by the same household each will have a relation of substitution. The study concluded that the main reason for motorcycle and a car was not cost, but utility factors, that the increase in reliability as well as convenience of a car may increase car ownership and reduce motorcycle ownership while increase of both reliability and convenience of a car may increase car ownership between 12\%-29\%.

Wedagama (2009a) carried out a study that examined household factors which influence car and motorcycle ownerships in the city of Denspar Bali using Poisson regression model. The study found that the increase in number

\section{ijtte 205}


of workers and students in a household may affect the probability of owning motorcycle by the household. Meanwhile, increase in number of family members and total travel distance may affect household preference to own a car. In addition, car capacity and other factors may increase household preference to own a car. None of these variables, however significantly influenced on both car and motorcycle ownerships. In other words, the household had a separate preference when purchasing either a car or a motorcycle. The sensitivity analyses show that a 50\% increase in number of workers and students may increase motorcycle ownership by 1 unit and a $50 \%$ increase in total distance by all household members may increase car ownership by 1 .

The existing literature have accounted for influence of different variables on car ownership in various parts of the world. However, Akure as a city in a developing country in sub Saharan Africa has its own peculiarities in terms of vehicle ownership characteristics. As such, this study endeavours to fill a research gap by investigating contributing factors to car ownership, based on the peculiarities of the residents, household factors, travel/mobility and socio-economic considerations in the city.

\section{Study Methodology}

\subsection{Study Area}

Data for this study were obtained from a questionnaire survey conducted between the months of May-July, 2016 in some selected households within Akure. Akure is a traditional Nigerian city and like other traditional Yoruba towns in the country, it existed long before the advent of British colonial rule in the country and has been the Ondo state capital since February 3, 1976. Akure is the capital of Ondo state in south west Nigeria with an estimated population figure of 588,000 as at 2016 (Millennium City Initiative, 2017). It is located between latitude 7020 " $\mathrm{N}$ and longitude 50" $\mathrm{E}$. An increase of immigrants to the town has led to an unprecedented rise in the city's population, thereby leading to a higher demand for residential accommodation and increased or improved transportation facilities. According Owolabi (2009) the traffic composition in the city is dominated by taxis (cars). Similarly, Oyedepo (2014) asserts that cars are the dominant mode of transportation in Akure metropolis, with about $49.82 \%$ of the traffic composition in the city. Fig. 1 is the map of Akure showing the study locations.

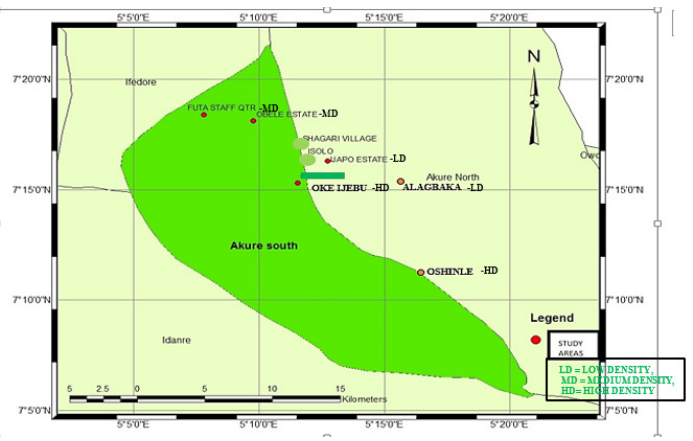

Fig. 1.

Map of Akure Showing the Study Locations 


\subsection{Data Description}

The study area was divided into three density zones namely High, Medium and Low population density zones with the survey yielding a return of 1002 questionnaire out of the 1181 distributed. Household data on the head and its relationship to other members, income, housing characteristics, and other socio-demographics; Information on each household's vehicles; Data about drivers, including information on travel were collected through the survey. In Fig. 2 is shown the number of questionnaire returned, the distribution of the questionnaire across the zones and the different locations. The data shows that the highest number of respondents as expected is from the high density zone since this is the most populated zone of all the zones sampled.
Data obtained from different zones based on land use were coded, imputed and analysed in SPSS 22 environment. SPSS 22 is a software package used for statistical analysis. SPSS is among the most widely used programs for statistical analysis in social science. In addition to statistical analysis, data management (case selection, file reshaping, creating derived data) and data documentation (a metadata dictionary is stored in the data file) are features of the base software. Statistical analysis such as descriptive statistics involving frequencies, cross tabulation, development of various charts such as bar charts, pie charts and tables were carried out on the data obtained using the software stated above. The multinomial Logit model of car owner was also developed using the SPSS 22 software.

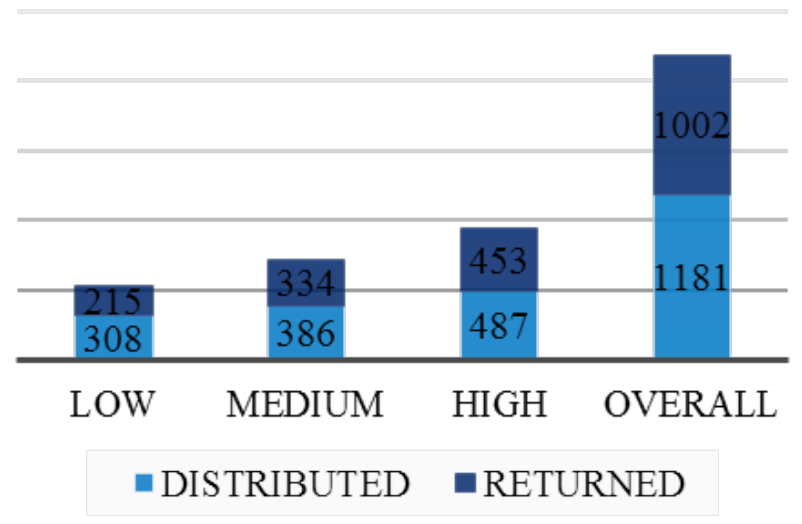

Fig. 2.

Questionnaire Returned from the Field Survey by the Authors

\subsection{Modelling Framework}

The Multinomial Logit model was used in developing the model for this study. The objective of the Multinomial Logit (MNL) Model is to estimate a function that determines the outcome probabilities. This study uses the MNL model to investigate the relationship that exists between household factors and car ownership (one, two and three or more) one ownership category is chosen as the reference category. 
The probability of each category is compared to the probability of the reference category. The 4 cars and above car category is the reference category for this study. For categories $i=2 \ldots \ldots . . . k$, the probability of categories are as follows (Wedagama, 2009b):

$$
\operatorname{Pr}(Y=i)=\frac{\exp \left(Z_{i}\right)}{1+\sum_{h=2}^{K} \exp \left(Z_{h i}\right)}
$$

Where:

$$
\alpha_{i}+\sum_{h=1}^{H} \beta_{i h} X_{i h}=Z_{i}
$$

For the reference category,

$$
\begin{aligned}
& \operatorname{Pr}(Y=1)=\frac{1}{1+\sum_{h=2}^{K} \exp \left(Z_{h i}\right)} \\
& \operatorname{Ln} \frac{\mathrm{P}(\mathrm{Y}=\mathrm{i})}{\mathrm{P}(\mathrm{Y}=1)}=\alpha_{\mathrm{i}}+\sum_{\mathrm{h}=1}^{\mathrm{H}} \beta_{\text {ih }} \mathrm{X}_{\mathrm{ih}}=\mathrm{Z}_{\mathrm{i}}
\end{aligned}
$$

Where: i: the number of ownership categories, $\beta_{\mathrm{ih}} \mathrm{X}_{\mathrm{ih}}$ : vectors of the estimated parameters and predictor variables respectively, $\operatorname{Ln} \frac{P(Y=i)}{P(Y=1)}$ : the probability of each categories with the first category as reference.
Eqs. (1- 3) above expressed the logit (log odds) as a linear function of the independent factors (Xs). Therefore, Eq. (3) allows for the interpretation of the logit weights for variables in the same way as in linear regressions.

\section{Results and Discussion}

\subsection{Descriptive Statistics}

The number of cars owned in the study area from the results obtained in the field survey were categorised into 1, 2, 3 and 4 cars\& above. The results show that most of the respondents who said they owned cars in the study area owned 1 car i.e. most of the respondents predominantly owned a single car as the 1 car group accounted for 365 of the households which owned cars. This is followed far behind by the 2 cars group which shows that 172 of the household surveyed said they owned 2 cars, then the 3 cars group with 70 cars and finally 13 households chose that they owned 4 cars and above. The remaining respondents did not indicate that they own cars which mean that a total of 620 households owned cars in the study area.

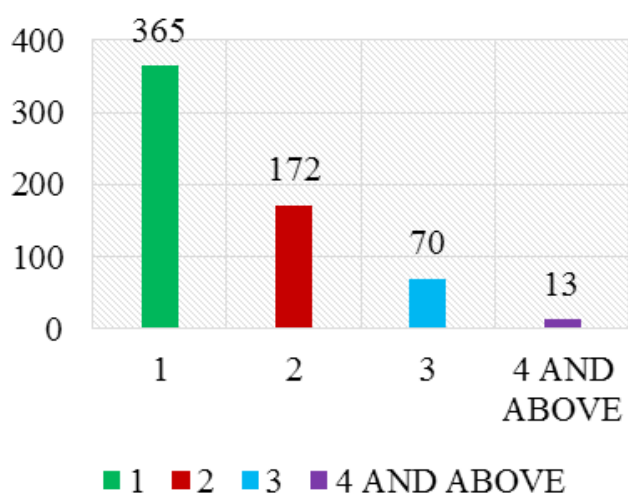

Fig. 3.

Car Categories Across the Zone 


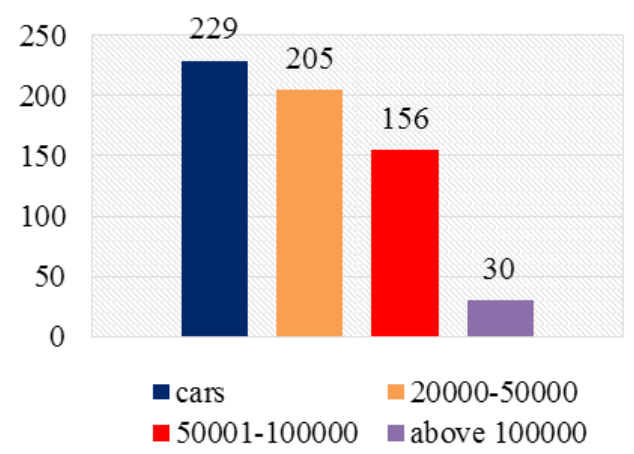

Fig. 4.

Income (in Naira) Against Number of Household with Cars

A comparison of the average monthly income (in Nigerian Naira) of the household with the number of cars owned across the zone showed that the number of cars owned increases as income increases. The peak income group i.e. 100,000 and above, accounted for 229 of households in which cars were owned, and this goes in a descending order to 205, 156 and 30 for the lower income categories respectively. This is as shown in Fig. 4 above which also shows the vehicle distribution across the zones for the different income categories. This means that a household is more likely to own a car as its average monthly income increases. This makes money a major determinant of car ownership in the study area.
In terms of academic qualification, the data gotten from the respondents as shown in Fig. 5 below reveals that most of the cars where owned by respondent with tertiary education qualification, this is followed by the secondary category and then primary school level with little or no ownership.

Households with tertiary, secondary and primary school level accounted for 466, 147 and 7 number of cars owned respectively across the zones. It therefore holds that increase in academic qualification leads to increase in the number of cars owned in Akure metropolis.

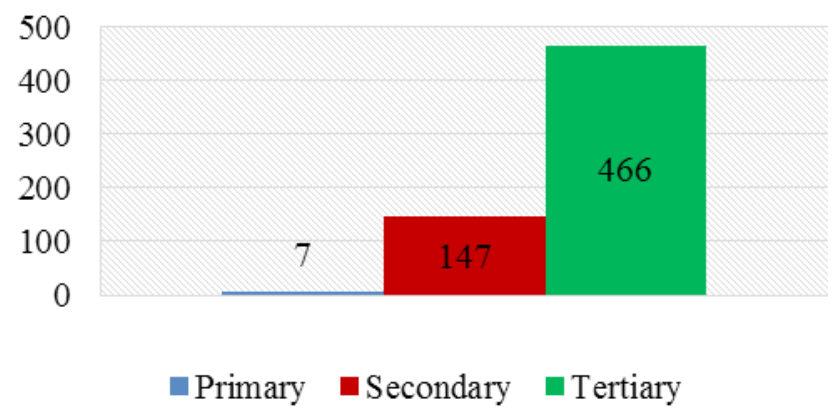

Fig. 5.

Number of Cars Owned and Academic Qualification 


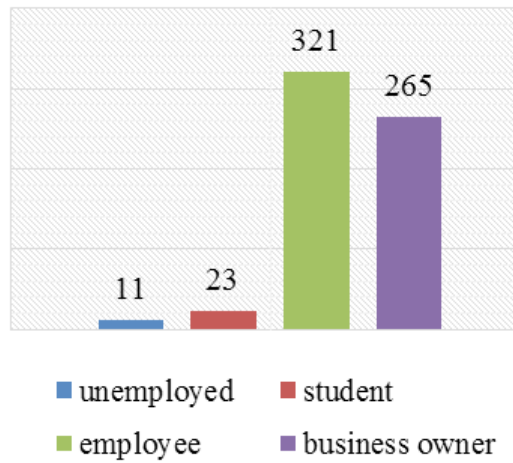

Fig. 6.

Number of Cars Owned and Occupation

In Fig. 6 it is seen that most of the respondents who own cars in the study area are those who say they are employed and those who are business owners. The students and unemployed accounted for very few of the cars owned with a combined total of 34 out of the whole number of cars owned. The business owner category owned a total of 269 cars while the employed category accounted for 324 of the cars owned. Most car owners in Akure are employees and business owners; increase in employment rate will lead to ownership of more cars.

\subsection{Car Ownership Model Estimates}

In selecting the variables for this model, the backward elimination process of multinomial logit model was followed using SPSS ver.22. All of reduced variables were selected using Likelihood Ratio ( $L R$ ) Chi -Square test (Wedagama 2009b).

The independent variables selected are monthly income, number of license holders, number of household members, number of employed household members, occupation and academic qualification. The variables and coding used are shown in Table 1 below. $\mathrm{L}_{\mathrm{N}}, \mathrm{H}_{\mathrm{N}}$ and $\mathrm{E}_{\mathrm{N}}$ are continuous variables while $\mathrm{I}, \mathrm{P}$ and $\mathrm{A}_{\mathrm{C}}$ are categorical variables. The dependent variable which is $\mathrm{C}_{\mathrm{N}}$ is also a categorical variable. See Table 1.

The 4 cars and above car ownership category of the dependent variable serves as the reference category for the model. Table 2 shows the variables that have a statistical significant effect on the degree of car ownership for households in Akure metropolis at the $95 \%$ confidence level. $\mathrm{L}_{\mathrm{N}}, \mathrm{H}_{\mathrm{N}}$ and $\mathrm{I}$ are the significant variables at the $95 \%$ confidence level i.e. $\mathrm{P}<0.05$ and for clarity purposes are the only variables included in Table 2.

Coefficients of the variables show that both $\mathrm{L}_{\mathrm{N}}$ and $\mathrm{H}_{\mathrm{N}}$ have negative influence on all car ownership categories while $\mathrm{I}_{2}$ has a positive influence on all categories. This to say that a unit change in $\mathrm{L}_{\mathrm{N}}$ and $\mathrm{H}_{\mathrm{N}}$ reduces the likelihood of owning $0,1,2$, and 3 cars as against 4 cars and above while it is increased with a unit change in $\mathrm{I}_{2}$. 


\subsubsection{Sensitivity Analysis of the Car Ownership Model}

Eqs. (4 -7) are the model equations derived from Table 2 and this is used to predict the number of cars owned in the study area. Using these equations sensitivity analysis was carried out considering only the variables that are statistically significant to all the car categories (i.e. $\mathrm{H}_{\mathrm{N}}$ and $\mathrm{I}_{2}$ ). The car ownership models were applied to test a number of policies and to measure their effects on car ownership in Akure metropolis (Cirillo and Liu, 2013). The following scenarios were tested:

\section{Table 1}

Model Variables

\begin{tabular}{|c|c|c|}
\hline Type of Variable & Variable Name & Notation \\
\hline \multirow{6}{*}{ Dependent Variable } & Number Of Cars & $\mathrm{C}_{\mathrm{N}}$ \\
\hline & No Car & $\mathrm{C}_{\mathrm{NO}}$ \\
\hline & One Car & $\mathrm{C}_{\mathrm{N} 1}$ \\
\hline & Two Cars & $\mathrm{C}_{\mathrm{N} 2}$ \\
\hline & Three Cars & $\mathrm{C}_{\mathrm{N} 3}$ \\
\hline & Four Cars and Above & $\mathrm{C}_{\mathrm{N} 4}$ \\
\hline \multirow{18}{*}{ Independent Variables } & Income (in Naira) & $\mathrm{I}$ \\
\hline & $<20,000$ & $\mathrm{I}_{1}$ \\
\hline & $20,000-50,000$ & $\mathrm{I}_{2}$ \\
\hline & $50,000-100,000$ & $\mathrm{I}_{3}$ \\
\hline & $>100,000$ & $\mathrm{I}_{4}$ \\
\hline & Occupation & $\mathrm{P}$ \\
\hline & Student & $\mathrm{P}_{1}$ \\
\hline & Employee & $\mathrm{P}_{2}$ \\
\hline & Bus Owner & $\mathrm{P}_{3}$ \\
\hline & Unemployed & $\mathrm{P}_{4}$ \\
\hline & Academic Qualification & $A_{C}$ \\
\hline & No Formal Education & $\mathrm{A}_{\mathrm{C} 1}$ \\
\hline & Primary Education & $\mathrm{A}_{\mathrm{C} 2}$ \\
\hline & Secondary Education & $\mathrm{A}_{\mathrm{C} 3}$ \\
\hline & Tertiary Education and Above & $\mathrm{A}_{\mathrm{C} 4}$ \\
\hline & License Holders & $\mathrm{L}_{\mathrm{N}}$ \\
\hline & Household Members & $\mathrm{H}_{\mathrm{N}}$ \\
\hline & Employed Household Members & $\mathrm{E}_{\mathrm{N}}$ \\
\hline
\end{tabular}

1. Change in household income: both a

$$
\begin{aligned}
& \log C_{\mathrm{N} 0}=1.120-6.234 \mathrm{~L}_{\mathrm{N}}-0.429 \mathrm{H}_{\mathrm{N}}+5.650 \mathrm{I}_{2} \\
& \log \mathrm{C}_{\mathrm{N} 1}=1.583-2.120 \mathrm{~L}_{\mathrm{N}}-0.353 \mathrm{H}_{\mathrm{N}}+5.423 \mathrm{I}_{2} \\
& \log \mathrm{C}_{\mathrm{N} 1}=1.583-2.120 \mathrm{~L}_{\mathrm{N}}-0.353 \mathrm{H}_{\mathrm{N}}+5.423 \mathrm{I}_{2} \\
& \log \mathrm{C}_{\mathrm{N} 1}=1.583-2.120 \mathrm{~L}_{\mathrm{N}}-0.353 \mathrm{H}_{\mathrm{N}}+5.423 \mathrm{I}_{2}
\end{aligned}
$$$$
\text { economic downturn) and a } 50 \%
$$
increase;

2. Change in number of household 
Table 2

Parameter Estimates of the Car Ownership Model

\begin{tabular}{|c|c|c|c|c|c|}
\hline Number of Cars & Variables & B & Std. Error & Sig. & $\operatorname{Exp}(B)$ \\
\hline \multirow{4}{*}{1} & Intercept & 1.120 & 1.097 & 0.000 & 3.065 \\
\hline & $\mathrm{L}_{\mathrm{N}}$ & -6.234 & 0.658 & 0.008 & 0.002 \\
\hline & $\mathrm{H}_{\mathrm{N}}$ & -0.429 & 0.161 & 0.008 & 0.651 \\
\hline & $\mathrm{I}_{2}$ & 5.650 & 1.846 & 0.002 & 284.308 \\
\hline \multirow{4}{*}{2} & Intercept & 1.583 & 1.053 & 0.000 & 4.870 \\
\hline & $\mathrm{L}_{\mathrm{N}}$ & -2.120 & 0.572 & 0.000 & 0.120 \\
\hline & $\mathrm{H}_{\mathrm{N}}$ & -0.353 & 0.156 & 0.024 & 0.703 \\
\hline & $\mathrm{I}_{2}$ & 5.423 & 1.784 & 0.002 & 226.511 \\
\hline \multirow{4}{*}{3} & Intercept & 2.507 & 1.040 & 0.000 & 12.268 \\
\hline & $\mathrm{L}_{\mathrm{N}}$ & -1.451 & 0.560 & 0.010 & 0.234 \\
\hline & $\mathrm{H}_{\mathrm{N}}$ & -0.272 & 0.156 & 0.031 & 1.034 \\
\hline & $\mathrm{I}_{2}$ & 3.658 & 1.778 & 0.040 & 38.773 \\
\hline \multirow{3}{*}{4} & Intercept & 3.949 & 1.056 & 0.001 & 51.883 \\
\hline & $\mathrm{H}_{\mathrm{N}}$ & -0.388 & 0.185 & 0.036 & 0.679 \\
\hline & $\mathrm{I}_{2}$ & 2.653 & 1.748 & 0.020 & 14.201 \\
\hline
\end{tabular}

Table 3

Sensitivity Application of the Car Ownership Model

\begin{tabular}{|l|l|l|l|l|l|}
\hline Car Ownership & Current & $\begin{array}{l}\text { Income } \\
+50\end{array}$ & $\begin{array}{l}\text { Income } \\
\mathbf{- 5 0}\end{array}$ & $\begin{array}{l}\text { HN } \\
+50\end{array}$ & $\begin{array}{l}\text { HN } \\
\mathbf{- 5 0}\end{array}$ \\
\hline 0 Car & $25.72 \%$ & $12.15 \%$ & $37.70 \%$ & $24.93 \%$ & $26.52 \%$ \\
\hline 1 Car & $35.14 \%$ & $18.59 \%$ & $45.98 \%$ & $35.38 \%$ & $34.88 \%$ \\
\hline 2 Cars & $16.43 \%$ & $21.02 \%$ & $8.90 \%$ & $17.23 \%$ & $15.67 \%$ \\
\hline 3 Cars & $22.66 \%$ & $47.88 \%$ & $7.42 \%$ & $22.41 \%$ & $22.89 \%$ \\
\hline 4 Cars and Above & $0.05 \%$ & $0.36 \%$ & $0.00 \%$ & $0.05 \%$ & $0.04 \%$ \\
\hline Total & $100 \%$ & $100 \%$ & $100 \%$ & $100 \%$ & $100 \%$ \\
\hline Total Number of Cars in Akure & 1608 & 2429 & 1016 & 1621 & 1595 \\
\hline Number of Households & 1181 & 1181 & 1181 & 1181 & 1181 \\
\hline Average Number of Cars Per Household & 1.36 & 2.06 & 0.86 & 1.37 & 1.35 \\
\hline Difference in Car Ownership & - & 821 & -592 & 13 & -13 \\
\hline \% Difference & - & $51 \%$ & $-37 \%$ & $0.80 \%$ & $-0.80 \%$ \\
\hline
\end{tabular}

The results of the different scenarios are shown in Table 3. From the test results, a 50\% increase in income significantly increases the number of cars owned in Akure metropolis by $51 \%$ while a decrease in income of the households by $50 \%$ also significantly reduces the number of cars owned by $37 \%$. However, increase in the number of household by $50 \%$ has little influence on the number of cars owned with just a $0.8 \%$ increase in the number of cars owned while a $50 \%$ decrease in the number of household members also has a little decrease of $0.8 \%$ in the number of cars owned in the metropolis. This goes to show that car ownership is very sensitive to changes in the income of households and therefore a major factor to consider when faced with the choice of owning a car in the study area.

The model summary is given in Table 4 and it shows an R-square value of 0.705 and a 
significance of 0.000 which implies that the independent variables have a significant influence on the number of cars owned. The high R-square value (close to unity) and significance $<0.05$ implies that the model is a good fitting for the variables selected and therefore validates the model.

Table 4

Car Ownership Model Summary

\begin{tabular}{|l|l|l|}
\hline R square & df & Sig. \\
\hline 0.705 & 1216 & 0.000 \\
\hline
\end{tabular}

\section{Conclusion}

This study developed a statistical model of car ownership for the city of Akure in south west, Nigeria so as to give understanding of factors affecting the continuous growth and usage of cars in the metropolis. The study's data were gotten from households in the study area through the administration of a wellstructured household questionnaire survey from May-July 2016. To enable adequate collection of data from a representative sample of the population, the study area was divided into three different zones classified based on their population densities; namely High, Medium and Low density zones. Statistical Package for Social Science (SPSS 22) was used for both descriptive statistics analysis and formulation of the Multinomial Logit Model of car ownership based on data obtained from the survey.

A total of 1181 households were earmarked for the survey out of this households, 1002 questionnaires were returned. Descriptive statistics show that the tendency of households to own cars in the metropolis increases with increase in the average monthly income of the household and increase in the academic qualification of the household head. The study also revealed that most household surveyed owned 1 car. While a very few owned 4 cars and above. Also a household in which the head has a means of livelihood either as a business owner or an employee stands a better chance of owning a car.

Model variables were selected using the backward elimination process of Multinomial Logit Model. Model estimates shows income category 2 and number of household members as the only variables having statistical significant influence on car ownership across the different car ownership categories (i.e. 0 car, 1 car, 2 cars, 3 cars, 4 cars and above). Coefficients of the two variables shows that income has positive influence on the number of cars while number of household members has a negative influence which means that the probability of owning a car increases with increase in income and reduces with increase in the number of household members.

The results of the model were used to test different scenarios so as to see what a $50 \%$ increase or decrease in either income or number of household members will have on the number of cars owned. Results of the test show that $50 \%$ increase in income significantly increase the number of cars owned in Akure metropolis by $51 \%$ while a decrease in income of the households by $50 \%$ also significantly reduces the number of cars owned by $37 \%$. However, increase in the number of household members by $50 \%$ has little influence of $0.8 \%$ increase in the number of cars owned while a $50 \%$ decrease in the number of household members also 
has a little decrease of $0.8 \%$ in the number of cars owned in the metropolis. This goes to show that car ownership is very sensitive to changes in the income of households and therefore a major factor to consider when faced with the choice of owning a car in the study area. R-square value of 0.705 and a significance of 0.000 implies that the model is a good fitting for the variables selected and therefore validates the model.

The study has been able to show that the tendency to own a car will increase with increase in earning capability of households in Akure such as in the periods of economic boom while the reverse is the case in periods of recession. It is expected that transportation policy makers will take these results into consideration when formulating transportation and car related policies that will help solve urban traffic problems in the city.

\section{References}

Choo, S.; Mokhtarian, P.L. 2004. What type of vehicle do people drive? The role of attitude and lifestyle in influencing vehicle type choice, Transportation Research Part A: Policy and Practice 38(3):201-22.

Cirillo, C.; Liu, Y. 2013. Vehicle Ownership Modelling Framework for the State of Maryland: Analysis and Trends from 2001 and 2009 NHTS Data, Journal of Urban Planning and Development 139(1): 1-11.

Dargay, J. 2002. Determinants of Car Ownership in Rural and Urban Areas: A Pseudo-Panel Analysis, Transportation Research Part E: Logistics and Transportation Review 38(5): 351-366.

Dargay, J.; Gately, D. 1999. Income's effect on car and vehicle ownership worldwide: 1960-2015, Transport action Research Part A: Policy and Practice 33(2): 101-138.
Egunjobi, L. 2002. Planning the Nigerian Cities for Better Quality of Life in Onakomaiya S.O. and Oyesiku O.O. (eds.). Environment, Physical Planning and Development in Nigeria, Department of Geography and Regional Planning, Olabisi Onabanjo University, Ago-Iwoye, Nigeria, 89-107.

Eno, O. 2007. Gender and transport: Women's proclivity to minimise car use in Akure, Pakistan Journal of Social Sciences 4(1):56-63.

Hsu, T.P.; Lin, Y.J. 2007. Multinomial Logit Model of Motorcycle and Car Ownership in Taiwan. In Proceeding of the Eastern Asia Society for Transportation Studies, 6-12.

Millennium City Initiative 2017. Akure, Nigeria. Available from internet: <http://mci.ei.columbia.edu/ millennium-cities/akure-nigeria/>.

Osita, N.; Semenitari, I.; Ugoani, A.; Ubanna, S.; Oyewale, D.; Ariole, A. 2003. Infrastructure: A rotten foundation, TELL Nigeria's Independent Weekly (23):47-50.

Owolabi, A.O. 2009. Paratransit Modal Choice in Akure, Nigeria-Applications of Behavioural Models. Institute of Transportation Engineers-ITE Journal 79(1): 54-58.

Oyedepo, O.J. 2014. Predictive Model of Traffic Flow at Urban Road Intersection: A Case Study of Akure Metropolis. Unpublished Thesis (PhD), School of Postgraduate Studies, Federal University of Technology Akure, Nigeria.

Rodriguez, J.P. 2013. The Geography of Transport Systems. Available from internet: <http://www.people. hofstra.edu/geotrans>.

Sinha, K.C. 2003. Sustainability and urban public transportation, Journal of Transportation. Engineering 129(4): 331-341.

Train, K. 1986. Qualitative Choice Analysis: Theory, Econometrics, and an Application to Automobile Demand. MIT Press, Cambridge, Mass $350 \mathrm{p}$. 
Wedagama, D.M.P. 2009a. The Analysis of Household Car and Motorcycle Ownerships using Poisson Regression (Case Study: Denpasar-Bali), Jurnal Teknik Sipil 16(2): 103-111.

Wedagama, D.M.P. 2009b. A Multinomial Logit Model for Estimating the Influence of Household Characteristics on Motorcycle Ownership: A Case Study in Denpasar City, Bali, Journal of Civil Engineering 29(1): 2-9.

Whelan, G. 2001. Methodological advances in modelling and forecasting car ownership in Great Britain. In Proceeding of the AET European Transport Conference, Cambridge, United Kingdom. 12 p. 